\title{
Propriedades em areias a verde com caulim para moldes de fundição
}

\author{
Properties in green sands with \\ kaolin for foundry molds
}

Luiz Ângelo de Paula Rosario ${ }^{1}$, Ludimilla da Silveira Ferreira ${ }^{1}$, Ivanir Luiz de Oliveira ${ }^{1}$

\footnotetext{
${ }^{1}$ Universidade Tecnológica Federal do Paraná, Laboratório de Fundição, Departamento de Engenharia Mecânica, Rua Doutor Washington Subtil Chueire, 330, 84017-220, Ponta Grossa - PR, Brasil. e-mail: luiz.angeloo@gmail.com, ludimilladsf@gmail.com, ivanir@utfpr.edu.com.
}

\section{RESUMO}

Os processos de moldagem em areias a verde são mundialmente utilizados na confecção de peças fundidas. Normalmente areias a verde são constituídas de areia de sílica, argila bentonítica, água e aditivos. O uso da bentonita sódica é amplamente difundido pelas suas qualidades superiores como ligantes. As argilas são compostas de argilominerais a base de silicatos hidratados de alumínio que comumente atingem certa plasticidade quando umedecidas. O que diferencia uma argila de outra é o tipo de estrutura e as substituições que podem ocorrer dentro desta estrutura; do alumínio por magnésio ou ferro, e do silício por alumínio ou ferro. Em todo caso o caulim é um mineral industrial importante nos vários mercados mundiais incluindo aplicações em cobertura e carga de papel, cerâmica, tintas, plásticos, borrachas, fibras de vidro e muitas outras utilizações. As misturas apresentam o teor de umidade que variou a relação água/argila de 0,1 a 0,3 para areia aglomerada com $10 \%$ de caulim. Para cada ensaio de compactabilidade, permeabilidade e resistência â compressão a verde foram elaborados 3 corpos de prova conforme ABNT com diferente relação areia/argila/água. Como enriquecimento do trabalho, foram avaliadas as propriedades permeáveis da areia sílica utilizada nos ensaios. Conclui-se que o caulim, sem aditivos, oriundo da cidade de Tijucas do Sul (PR), apresenta resistência mecânica â compressão aceitável para a sua utilização em fundição, entretanto, a permeabilidade não foi satisfatória em nenhuma composição. Já a compactabilidade foi aceitável apenas quando a umidade causou o inchamento da areia, sendo que neste ponto, houve também a máxima resistência mecânica à compressão.

Palavras-chave: Argilas. Caulim. Fundição. Areia a verde. Materiais refratários.

\section{ABSTRACT}

Green sand molding processes are used worldwide in the manufacture of castings. Usually green sands are made up of silica sand, bentonite clay, water and additives. The use of sodium bentonite is widespread for its superior qualities as binders. Clays are composed of clay minerals based on hydrated aluminum silicates that commonly reach a certain level of plasticity when moistened. What differentiates one clay from another is the type of structure and the substitutions that can occur within this structure; of aluminum by magnesium or iron, and of silicon by aluminum or iron. In any case, kaolin is an important industrial mineral in the various world markets including applications in covering and loading paper, ceramics, paints, plastics, rubbers, glass fibers and many other uses. The mixtures present the moisture content that varied the water / clay ratio from 0.1 to 0.3 for sand agglomerated with $10 \%$ kaolin. For each compactability, permeability and resistance to compression test in green, 3 specimens were prepared according to ABNT with different sand / clay / water ratio. As an enrichment of the work, the permeable properties of the silica sand used in the tests were evaluated. It is concluded that kaolin, without additives, from the city of Tijucas do Sul (PR), presents acceptable mechanical resistance to compression for its use in foundry, however, the permeability was not satisfactory in any composition. Compactability was acceptable only when moisture caused the sand to swell, and at this point, there was also maximum mechanical resistance to compression.

Keywords: Clays. Kaolin. Foundry. Sand to green. Refractory Materials. 


\section{INTRODUÇÃO}

O processo de fundição de peças representa o caminho mais curto entre a matéria-prima metálica e as peças acabadas, em condições de uso. Consiste principalmente na produção de peças metálicas que são obtidas a partir do vazamento de um metal líquido em caixas de moldagem, com machos montados em seu interior, que caracterizará a peça após a solidificação do metal. A fundição emprega nos seus processos: modelos, moldes e machos que promovem às peças fundidas a sua conformação, de acordo com as etapas de moldagem, fusão e acabamento [1].

Umas das grandes características da indústria de fundição é uso intensivo de mão de obra e matériasprimas. Produzindo peças fundidas em ferro, aço e ligas não ferrosas. De acordo com a Associação Brasileira de Fundição (ABIFA), no Brasil, no ano de 2018, as indústrias produziram cerca de 2.283.379 milhões toneladas de fundidos, sendo que, para ferro ela produziu 1.840 .152 toneladas, para aço 244.008 toneladas e para os não-ferrosos 199.219 toneladas. Deste modo, sua maior produção ocorreu na região sul do país com 888.597 toneladas [2].

Apesar do desenvolvimento alcançado pelos métodos especiais para o processo de fundição há várias técnicas de fundir peças metálicas, podendo ser classificadas como: fundição sob pressão, processo de $\mathrm{CO}_{2}$, processo Shell Molding, processo de cera perdida e o processo de areia a verde sendo o mais utilizado devido seus altos rendimentos obtidos e podem ser reutilizáveis [3]. Para o processo de areia a verde geralmente são utilizadas areia de sílica, zircônita, cromita, aglomeradas por ligantes como a argila, aditivos e água [4].

A composição da argila que chamamos de bentonita apresenta silicato de alumina hidratado que contém em sua composição silício, alumínio, ferro, cálcio, magnésio, potássio e sódio. É formada por lamelas, sendo classificada pela espessura das mesmas. $\mathrm{O}$ fator principal da água na mistura da areia de moldagem é a escoabilidade, consistência e plasticidade definindo a característica de seu uso, obtendo moldes uniformemente compactados, que reproduzem fielmente as dimensões do modelo. Sua função coesiva permite que a resistência da caixa de moldagem seja suficiente durante o vazamento, não permitindo assim que a mesma se rompa durante o processo [5].

$\mathrm{O}$ argilomineral caulinita é encontrado na natureza e ainda é considerado um dos minerais mais abundantes em solos e sedimentos. É formado pelo empilhamento regular de camadas 1:1, sendo formada por uma folha tetraédrica, constituída de silício coordenados tetraedricamente por átomos de oxigênio $\left(\mathrm{SiO}_{4}\right)$, e outra folha octaédrica, constituída por alumínio coordenados octaedricamente a oxigênio e grupamentos $\mathrm{OH}$, suas partículas de cauliníticas não são facilmente quebradas, e as camadas desse argilomineral não são facilmente separáveis [6].

As argilas cauliníticas possuem partículas de caulinita formada normalmente por placas hexagonais apresentando a fórmula estrutural da cela unitária $\mathrm{Al}_{4} \mathrm{Si}_{4} \mathrm{O}_{10}(\mathrm{OH})_{8}$ com composição percentual expressa em termos de óxidos de $\mathrm{SiO}_{2}-46,54 \% ; \mathrm{Al}_{2} \mathrm{O}_{3}-39,50 \% ; \mathrm{H}_{2} \mathrm{O}-13,96 \%$ [7]. A maioria das partículas grandes tendem a formar empilhamentos de partículas menores. Além disso, as argilas cauliníticas possuem baixa capacidade de troca catiônica e menor plasticidade comparativa entre às argilas, devido à forte ligação entre as camadas de clivagem. A modificação estrutural das argilas cauliníticas, pela intercalação de agentes tensoativos, visa estudar/entender a capacidade de dispersão em pastas/soluções aquosas [8].

O objetivo deste trabalho é analisar as propriedades em areias a verde com caulim para moldes de fundição, buscando materiais alternativos para o setor de fundição. para isto, adota-se critérios convencionais pela indústria para a caracterização das matérias primas e misturas e, com o conhecimento da compactabilidade, resistência à compressão a verde e da permeabilidade em areias a verde com caulim.

\section{MATERIAIS E MÉTODOS}

$\mathrm{O}$ trabalho consistiu em analisar as propriedades mecânicas da areia a verde aglomerada com caulim. O caulim analisado foi oriundo da cidade de Tijucas do Sul, Paraná e foi extraído pela empresa Paraná Mineração. Todos os ensaios foram realizados no laboratório de fundição (CETEM) da Universidade Tecnológica Federal do Paraná, campus Ponta Grossa.

Quanto ao recebimento da amostra foi conferida em balança, a qual forneceu o valor de 64,4kg. Após o recebimento e conferência do material da análise, foram determinados os passos a serem executados. Inicialmente os materiais foram analisados, a areia de sílica realizou o ensaio de teor de umidade, distribuição granulométrica, módulo de finura, teor de finos e a permeabilidade. 


\subsection{Determinação do teor de umidade}

A determinação do teor de umidade foi realizada conforme determina a CEMP 068. Foram separadas 3 amostras de mistura e pesadas em um vidro, previamente, as porções contendo aproximadamente $50 \mathrm{~g}$ foram pesadas com o auxílio da balança analítica de precisão e anotados os respectivos valores em massa. Em seguida, a amostra foi introduzida na estufa com temperatura em torno de $120^{\circ} \mathrm{C}$ por um período de 2 horas. Após este período a mistura permaneceu em resfriamento por 30 minutos até atingir a temperatura ambiente, a massa de cada amostra foi aferida em balança e, em seguida a amostra foi reintroduzida na estufa por 1 hora e resfriada por 30 minutos. Seguiu-se o procedimento por 6 vezes até que os valores da massa ficassem estáveis. Quando da estabilização da massa da amostra, a estufa foi desligada e a amostra ficou em seu interior até que ambos chegassem à temperatura ambiente.

\subsection{Distribuição Granulométrica}

A realização do ensaio teve início com a limpeza e a pesagem de cada uma das peneiras e do fundo para determinação do peso inicial de cada componente. Conforme recomenda a CEMP 081, foi efetuado o peneiramento da amostra de areia e anotado os valores. Para a execução do ensaio, uma porção de aproximadamente $20 \mathrm{~g}$ de areia foi pesada em balança e despejada sobre o conjunto de peneiras da série padrão da ABNT, as quais foram tampadas para o início do procedimento. Durante o experimento as peneiras permaneceram vibrando por 12 minutos com intensidade regulada em $80 \%$ da capacidade máxima do vibrador mecânico. Após o peneiramento, cada uma das peneiras foi pesada novamente com o material retido. Posteriormente, após a pesagem de todas as peneiras, o material retido foi despejado sobre uma folha, com a ajuda de um pincel e pesado em uma balança. Os valores foram anotados em uma planilha, conforme determina a CEMP 081.

\subsection{Ensaios de permeabilidade}

Elaborou-se a seleção, através do peneiramento, de areia base do tipo sílica para conhecimento da sua permeabilidade. Peneirou-se uma quantidade com $170 \mathrm{~g}$ de areia para a confecção de um CP. Durante a realização do ensaio foram seguidos os passos do item 6 da NBR 12634, a CEMP 68 e CEMP 80. O ensaio iniciou-se com a pesagem de $160 \mathrm{~g}$ da mistura em balança, para confeccionar um CP do tipo $1 \mathrm{~A}$ conforme descrito na CEMP E-10. Em seguida, com o cilindro posicionados sob o funil com peneira, foram despejados o material de forma a preencher o interior do cilindro.

Em relação à peneira do ensaio de permeabilidade, esta é constituída de duas malhas, sendo uma fina e outra grossa. A malha fina deve estar direcionada para dentro do cilindro e ficar em contato com o CP. A malha grossa, portanto, deverá estar direcionada para fora do cilindro. Isto ocorre porque a malha grossa tem a função de fazer o primeiro direcionamento do ar para que a malha fina faça o direcionamento do fluxo de ar para dentro do CP.

Em seguida, a porção de $160 \mathrm{~g}$ de areia foi adicionada. E então, a segunda peneira pode ser colocada sobre a parte superior do CP. Com o cilindro preenchido e as peneiras posicionadas, o conjunto pode ser colocado sob o martelete, com cuidado para evitar a pré-compactação. Em seguida foram efetuadas as três percussões. Finalmente o $\mathrm{CP}$, embutido no cilindro e confinado entre as peneiras, pode ser acoplado à extremidade emborrachada do permeâmetro.

No permeâmetro, após o posicionamento do $\mathrm{CP}$, a cúpula do aparelho foi puxada para cima, apertando-se o botão superior que permite a entrada de ar. A cúpula, após posicionada na capacidade de 2 litros do equipamento, foi solta. Em seguida a alavanca do equipamento foi girada do modo "FECHADO" para o modo "ENSAIO", iniciando assim o experimento. O valor da permeabilidade pode ser aferido diretamente no mostrador lateral em escala, o qual fornece valores em unidades de centímetros à quarta sobre gramas vezes minutos ( $\left.\mathrm{cm}^{4} / \mathrm{g} \cdot \mathrm{min}\right)$. Para a consideração do valor como verdadeiro e absoluto foram confeccionados três corpos de prova e considerado o valor da média aritmética de 3 ensaios. Em relação à escala do equipamento, houve o cuidado com o detalhe de que, o permeâmetro utilizado continha 3 escalas, sendo elas, da esquerda para a direita, escala de baixa permeabilidade, escala de calibração e escala de alta permeabilidade.

A escala de calibração deve ser utilizada durante a aferição de funcionamento do equipamento antes da realização do ensaio. Com o auxílio de um CP padrão, feito de borracha e com um orifício que pode ser de $0,5 \mathrm{~mm}$ ou de $1,5 \mathrm{~mm}$, deve-se realizar um experimento com este CP padrão acoplado ao cilindro e ambos acoplados ao equipamento. Para cada tamanho de orifício do $\mathrm{CP}$, há um bico correto a ser utilizado no equipamento no local onde o cilindro foi acoplado. No caso do equipamento utilizado neste experimento, os bicos continham a descrição $\mathrm{P}$ e $\mathrm{G}$, indicando $0,5 \mathrm{~mm}$ e $1,5 \mathrm{~mm}$ consecutivamente. 
Com o bico e CP padrão contendo o orifício de mesmo diâmetro, o ensaio deve ser efetuado. O resultado esperado é o número 10 da escala do centro. Para a escala da esquerda que é a de baixa permeabilidade, deve ser utilizado o bico de orifício $0,5 \mathrm{~mm}$. Tal combinação é utilizada para a avaliação de grão com pouca permeabilidade. Nota-se que a escala parte de 0 e vai até o valor de $50 \mathrm{~cm}^{4} / \mathrm{g} . \mathrm{min}$.

Para a escala da extremidade direita, a qual representa a alta permeabilidade, deve ser acoplado o bico com orifício de $1,5 \mathrm{~mm}$. Com o equipamento configurado desta maneira, materiais que apresentam valores de permeabilidade acima de $35 \mathrm{~cm}^{4} / \mathrm{g}$.min podem ser avaliados. O valor máximo apresentado para este equipamento é de $2500 \mathrm{~cm}^{4} / \mathrm{g} \cdot \mathrm{min}$.

\subsection{Preparação do caulim}

Quando do recebimento do caulim, foi realizado uma inspeção visual e numa amostra foi realizada a lavagem para a identificação de possíveis impurezas.

Foi realizado uma desaglomeração do caulim utilizando um moinho de martelos, em seguida realizou-se um quarteamento em duas etapas, a pilha cônica e a pilha alongada. O material foi despejado misturado com uma pá, formando a pilha cônica em forma de domo.

O material foi coletado com o auxílio de uma concha e despejado sobre uma lona para formar pilha alongada. A quantidade de material no coletor foi espalhada completamente de maneira uniforme do início ao final da pilha alongada.

Sobre a pilha alongada, a distribuição do material foi realizada de forma alternada entre as extremidades, de modo que, os despejos ímpares iniciassem em uma extremidade, e os despejos pares, na extremidade oposta. Com todo o material transferido da pilha cônica para a pilha alongada, foi realizado um corte nas duas extremidades onde retirou-se o material e despejando-o sobre a pilha.

Por fim, a pilha alongada foi dividida longitudinalmente em 2 porções e transversalmente em 17 porções idênticas com aproximadamente $0,3 \mathrm{~m}$ de largura. A numeração de cada uma das porções ocorreu da direita para a esquerda em ambos os lados da pilha. Neste caso com 17 porções, o número 1 era oposto ao número 17, o número 2 oposto ao número 16 e assim sucessivamente. As recomendações da CEMP E-01 não determinam tamanho exato para as repartições, entretanto, deixa claro que devem seguir um padrão e serem uniformes no tamanho. As frações de caulim foram armazenadas, catalogadas e lacradas.

\subsection{Elaboração da mistura padrão}

Para a elaboração da mistura padrão foi idealizado a metodologia de porcentagens por acréscimo de massa a cada experimento. Para a construção desta, foi previamente estabelecido a relação água/argila, que foi o fator variante do experimento, e a relação argila/areia que permaneceu fixa por todo o ensaio. Com a determinação das relações, foram calculadas as porcentagens relativas de cada componente e em seguida, partindo de uma massa inicial de areia base, foram calculadas as massas de argila e de água.

Realizou-se primeiramente uma homogeneização da amostra utilizando um misturador de rolos. Durante o processo, foi seguido a NBR 12292, NBR 12669 e CEMP 068.

Após a primeira mistura da areia, foram realizados os primeiros ensaios de compactabilidade, permeabilidade e R.C.V. e, para o próximo ensaio. Foi acrescentado ao material misturado, dois pontos distintos de entrada de água e misturado por mais 700 voltas. Para cada um dos ensaios realizados, foram coletadas amostras da areia para a conferência do teor de umidade real após o procedimento de mistura dos componentes.

Para a realização do ensaio de compactabilidade foram seguidas as determinações contidas na CEMP 65. Durante a execução do ensaio foi coletada, uma quantidade de areia superior àquela necessária para o preenchimento do cilindro. Após o despejo de areia sobre a peneira e funil, havia um transbordo do excesso de areia, já esperado, sendo nivelado pela superfície superior.

O nivelamento da mistura ocorreu mediante raspagem do material sobressalente. A raspagem foi realizada com o posicionamento perpendicular do raspador sobre a face superior do cilindro, partindo ao meio o montante de areia e, arrastando o excesso para fora do cilindro à direita e à esquerda. Com a amostra nivelada, o cilindro era posicionado sob o martelete com cuidado evitando a pré-compactação durante o manejo ou posicionamento sobre o equipamento. Com o cilindro sob o martelete, havia um cuidado adicional para garantir que apenas o peso do martelete, colocado de maneira cuidadosa, fizesse a primeira compactação de contato, evitando ao máximo um primeiro impacto indesejável.

Em seguida, eram executadas três percussões no martelete de forma a compactar o material, sendo estas também executadas com cuidado, evitando que durante o giro da alavanca, o martelete ultrapassasse a altura má- 
xima que deveria atingir antes do impacto.

Ao final das três badaladas e com o martelete solto na última posição de impacto, o valor em porcentagem pode ser aferido diretamente na escala do instrumento. Os ensaios foram realizados em triplicata, adotando-se a média aritmética das amostras.

Para a realização do ensaio de resistência a verde foram executados os procedimentos descritos na NBR 12669 e CEMP 60 que estabelece a aplicação de uma carga de forma constante sobre as extremidades do CP até obter a ruptura. Após a elaboração da mistura padrão, foi peneirado uma quantidade de $170 \mathrm{~g}$ de areia a verde para a confecção de um CP padrão, conforme determina a CEMP E10. Em seguida o material foi compactado com o martelete, retirado do cilindro com o extrator e acoplado à máquina de ensaios de R.C.V, a qual foi previamente verificada e nivelada, tendo seu marco zero em $0,5 \mathrm{~N} / \mathrm{cm}^{2}$. Após a previa conferência e calibração do equipamento, o CP foi posicionado. Em seguida com o giro da manivela, de forma contínua e progressiva, a carga de compressão foi aplicada, até atingir a ruptura do CP.

O resultado da pressão exercida pode ser aferido no próprio equipamento, o qual é dotado de escala. A unidade de medida para o ensaio é em N/ $\mathrm{cm}^{2}$. Para a adoção do valor verdadeiro e absoluto foram confeccionados três ensaios, cada uma com um CP diferente e então foi considerado o valor da média aritmética de 3 ensaios.

Em todos os ensaios, foram coletadas $20 \mathrm{~g}$ de amostra de cada uma das misturas para a determinação do teor de umidade real.

As amostras foram secadas em estufa de maneira semelhantes ao procedimento da determinação do teor de umidade antes dos ensaios. Sabe-se que durante a mistura a areia a verde perde umidade para o ambiente, tendo grande déficit quando a temperatura ambiente está acima de aproximadamente $25^{\circ} \mathrm{C}$ e quando o misturador está sem a tampa. O simples fato de o misturador realizar seu trabalho e homogeneizar a areia, já causa uma perda significativa de umidade para o ambiente.

\section{RESULTADOS E DISCUSSÃO}

A preparação da areia de sílica consistiu da análise dos teores de umidade atual, granulometria e permeabilidade. Para todas as análises foi desconsiderada a presença de Argila AFS uma vez que a Areia Base comercial utilizada no trabalho passa por rigoroso tratamento de lavagem e secagem eliminando esta contaminação natural.

Para a verificação da determinação do teor de umidade na areia base, foram coletadas 3 amostras com $20 \mathrm{~g}$ cada, as quais foram inicialmente pesadas, secadas em estufa e, ao final, pesadas novamente. $\mathrm{O}$ valor em porcentagem de água das amostras está representado na tabela 1.

Tabela 1: Teor de umidade da areia base

\begin{tabular}{c|c|c|c|c}
\hline AMOSTRA & PESO INICIAL (G) & PESO FINAL (G) & PESO DO RECIPIENTE (G) & UMIDADE (\%) \\
\hline 1 & 129,40 & 128,91 & 109,42 & 2,45 \\
\hline 2 & 63,74 & 63,23 & 43,76 & 2,55 \\
\hline 3 & 64,22 & 63,73 & 44,22 & 2,45 \\
\hline Média & \multicolumn{4}{|c}{} \\
\hline
\end{tabular}

Nota-se uma umidade elevada, sendo de grande importância a consideração deste valor. Em alguns casos a relação areia/argila abaixo de 0,1 e a relação água/argila de 0,249 podem estar muito próximas ao ponto de máxima resistência à verde. Assim, durante a realização dos ensaios, a adição de pouca quantidade de água somada à umidade presente já poderia fazer com que a areia a verde atingisse ou ultrapassasse o ponto máximo de resistência à verde.

Todo o material utilizado nesta segunda etapa de ensaios foi peneirado por meio do uso de peneira malha 2 $\mathrm{mm}$, segundo ABNT 10. Após o peneiramento, a amostra inicial de 18,54kg foi quarteada e dividida em duas amostras com o auxílio do Quarteador Jones. A primeira amostra continha $9,54 \mathrm{~kg}$ e a segunda $9,0 \mathrm{~kg}$. A amostra com $9,54 \mathrm{~kg}$ de areia foi colocada inteiramente dentro do misturador. Percebeu-se então que, esta quantia preenchia apenas $40 \%$ ( $8 \mathrm{~cm}$ em altura) da capacidade máxima (20 cm em altura) do equipamento. 
Assim, completou-se com a outra amostra. Para que a segunda amostra fosse acrescentada, esta foi novamente quarteada e, uma parte com 2,22kg foi adicionada. Assim, o misturador atingiu cerca de $50 \%$ da sua capacidade, contendo a massa de $11,76 \mathrm{~kg}$ em areia a verde. Com esta quantidade de material, notou-se que a areia a verde respeitava o limite máximo estabelecido por norma e também satisfazia o limite mínimo observado por experiência. Ou seja, o material mantinha contato com os dois rolos do misturador.

Para a determinação da granulometria, uma amostra de $20 \mathrm{~g}$ foi pesada e, através do peneiramento, pode-se determinar o módulo de finura, concentração e teor de finos, conforme demonstra a Tabela 2 e no Gráfico 1 .

Tabela 2: Distribuição granulométrica da areia base

\begin{tabular}{c|c|c|c|c}
\hline PENEIRAS (No) & PESO PENEIRA VAZIA(G) & PESO PENEIRA + MATERIAL (G) & RETENÇÃO (G) & RETENÇÃO (\%) \\
\hline 6 & 362,87 & 362,87 & 0,00 & 0,00 \\
\hline 12 & 328,08 & 328,08 & 0,00 & 0,00 \\
\hline 20 & 255,79 & 255,79 & 0,00 & 0,00 \\
\hline 30 & 234,27 & 235,99 & 0,72 & 3,60 \\
\hline 40 & 246,94 & 248,43 & 1,49 & 7,45 \\
\hline 50 & 246,38 & 247,72 & 1,34 & 6,70 \\
\hline 70 & 228,46 & 231,75 & 3,29 & 16,45 \\
\hline 100 & 225,82 & 231,09 & 5,27 & 26,35 \\
\hline 140 & 227,23 & 230,69 & 3,46 & 17,30 \\
\hline 200 & 221,95 & 224,91 & 2,96 & 14,80 \\
\hline 270 & 208,42 & 209,13 & 0,71 & 3,55 \\
\hline Prato & 305,65 & 306,41 & 0,76 & 3,80 \\
\hline
\end{tabular}

Gráfico 1: Distribuição granulométrica da areia base

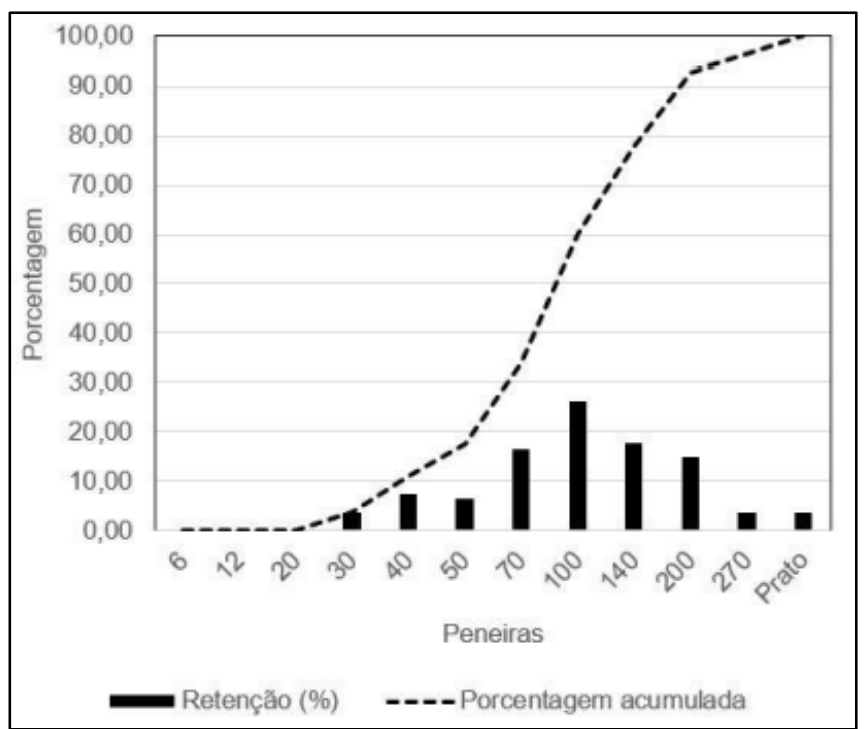

O módulo de finura, apresentou o valor de MF \#88,82, característico de uma areia fina. A concentração de 74,9\% foi obtida com o somatório da porcentagem das peneiras 70, 100, 140 e 200, pois estas apresentaram mais de $10,0 \%$ de retenção. E o teor de finos de 22,15\% pode ser determinado com a somatório das porcentagens das últimas duas peneiras mais ao fundo. 


\subsection{Compactabilidade, permeabilidade e resistência à verde}

A partir da umidade inicial da areia da areia de 2,49\% representando uma relação água/argila de 0,221, iniciou-se o experimento. Efetuou-se a mistura por 700 voltas e após este período, ensaios de compactabilidade, permeabilidade e R.C.V. foram realizados. A média aritmética de 3 resultados de cada composição foi considerada. Ao todo foram elaboradas 17 composições totalizando 51 ensaios. Os dados estão representados na Tabela 3 e no Gráfico 2.

Tabela 3: Compactabilidade, permeabilidade e resistência à verde

\begin{tabular}{|c|c|c|c|c|c|}
\hline COMPOSIÇÕES & $\begin{array}{l}\text { COMPACTABILIDADE } \\
(\%)\end{array}$ & $\begin{array}{c}\text { PERMEABILIDADE } \\
\left(\mathrm{cm}^{4} / \mathrm{g} \cdot \mathrm{min}\right)\end{array}$ & $\begin{array}{c}\text { RES. À VERDE } \\
\left(\mathbf{N} / \mathbf{c m}^{2}\right)\end{array}$ & $\begin{array}{l}\text { TEOR DE UMI- } \\
\text { DADE (\%) }\end{array}$ & ÁGUA/ARGILA \\
\hline 1 & 21 & $<35$ & 2,58 & 1,00 & 0,090 \\
\hline 2 & 23 & 27 & 3,25 & 1,47 & 0,133 \\
\hline 3 & 25 & 31 & 3,5 & 1,90 & 0,172 \\
\hline 4 & 24 & 33 & 3,08 & 2,22 & 0,201 \\
\hline 5 & 24 & 32 & 2,75 & 2,40 & 0,217 \\
\hline 6 & 27 & 34 & 3,17 & 2,67 & 0,241 \\
\hline 7 & 25 & 33 & 3,5 & 2,69 & 0,243 \\
\hline 8 & 29 & 36 & 3,92 & 2,78 & 0,251 \\
\hline 9 & 30 & 36 & 4,00 & 3,06 & 0,276 \\
\hline 10 & 32 & 36 & 4,75 & 3,40 & 0,307 \\
\hline 11 & 30 & 35 & 5,00 & 63,67 & 0,332 \\
\hline 12 & 31 & 32 & 5,00 & 3,94 & 0,356 \\
\hline 13 & 36 & 37 & 5,75 & 4,12 & 0,372 \\
\hline 14 & 35 & 35 & 5,67 & 4,23 & 0,382 \\
\hline 15 & 42 & 33 & 6,5 & 4,39 & 0,397 \\
\hline 16 & 50 & 32 & 6,42 & 4,49 & 0,406 \\
\hline 17 & 57 & 34 & 5,50 & 4,75 & 0,429 \\
\hline
\end{tabular}

Gráfico 2: Compactabilidade, permeabilidade resistência à verde

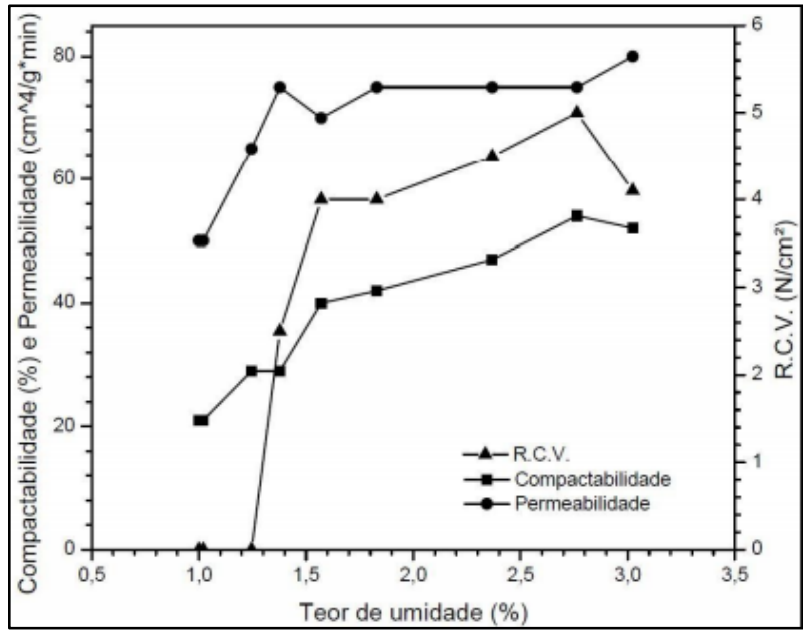

Nesta segunda etapa foram necessárias 17 composições diferentes, aumentando sempre a relação água/argila para encontrar o ponto máximo de R.C.V. e confirma-lo com a queda deste valor por mais 6 ensaios consecutivos de 2 composições diferentes. 
Para a compactabilidade o valor ideal varia entre $57 \%$ e $59 \%$. Sendo este valor atingido apenas no $17^{\circ}$ ensaio onde o resultado foi $57,67 \%$. Nos demais casos quando a umidade estava abaixo do ponto ótimo a compactabilidade apresentou valores insatisfatórios.

A permeabilidade foi insatisfatória, apresentando o valor máximo de $37 \mathrm{~cm}^{4} / \mathrm{g}$.min no $13^{\circ}$ ensaio, representando apenas 46,25\% do máximo aferido na areia a verde com $10 \%$ de caulim. Estes valores podem ser atribuídos ao pequeno tamanho de partícula e presença de finos na areia base de sílica. A permeabilidade das amostras foi considerada insatisfatória para uma boa areia de fundição, pois valores tão baixos quanto os obtidos durante os ensaios, impedem a fuga adequada dos gases durante a vazão do metal líquido.

\section{CONCLUSÕES}

Com base nos resultados observados foi possível concluir que:

A caulinita, com baixa área superficial e baixa capacidade de troca de cátions foi capaz de fornecer a aglomeração necessária para uma areia a verde.

As propriedades AFS, quanto em teores ótimos de umidade, foram de acordo com o recomendado para a compactabilidade e R.C.V. e, abaixo do recomendado para a permeabilidade.

Pelo que foi observado, os teores ótimos de água, dados em relação água/argila, foram de 0,276 e 0,439 para areia a verde com $10 \%$ de caulim, conforme literatura que valores acima de 0,25 forneciam bons resultados.

\section{AGRADECIMENTOS}

Agradecemos a Paraná Mineração de Tijucas do Sul pelo fornecimento da argila utilizada neste trabalho.

\section{BIBLIOGRAFIA}

[1] CARNIN, R.L.P. Reaproveitamento do resíduo de areia verde de fundição como agregado em misturas asfálticas, Tese de D.Sc., UFPR, Curitiba, PR, Brasil, 2008.

[2] ASSOCIAÇÃO BRASILEIRA DE FUNDIÇÃO. "Guia Abifa de Fundição: Anuário e Serviços", $A B I F A$, pp. 1-3, 2018.

[3] PINO, R.L., HERNÁNDEZ, R.J, VALENCIA, M.E., et al. "Desarrollo de una nueva mezcla auto fraguante para machos de fundición”, Cerámica y Vidrio, v. 48, n. 2, pp. 81-90, 2009.

[4] BALDAM, R.L., VIEIRA, E.A. "Fundição: Processos e tecnologia correlatas". 1. ed., São Paulo: Érica, 2013.

[5] MENEZES, R.R.; JÚNIOR, A.M.M., SANTANA, L.N.L., et al. "Comportamento de expansão de argilas bentoníticas organofílicas do estado da Paraíba”, Cerâmica, v. 54, n. 331, pp. 152-159, 2008.

[6] CAGLAR, B., TABAK, A., AFSIN, B., et al. "Covalent grafting of pyridine-2-methanol into kaolinite layers”, Journal of Molecular Structure, v. 1032, pp. 12- 22, 2013.

[7] DE RESENDE, E.I.P., MANGRICH, A.S., MANGONI, A.P., et al. "Estudo espectroscópico de compósito obtido da reação no estado sólido entre um complexo mononuclear de vanádio (IV) e caulinita", Química Nova, v. 35, pp. 257-261, 2012.

[8] GIRARDI, F. Modificação superficial de argila caulinítica: oclusão de agentes tensoativo, Tese de D.Sc., UFSC, Florianópolis, SC, Brasil, 2013.

\section{ORCID}

Ludimilla da Silveira Ferreira

Luiz Angelo de Paula do Rosario

Ivanir Luiz de Oliveira https://orcid.org/0000-0003-4030-5135

https://orcid.org/0000-0001-7884-8595

https://orcid.org/0000-0002-8208-2382 